\title{
A preservação da informação digital nos arquivos das IFES da Região Sul do Brasil
}

\author{
Murilo Billig Schäfer \\ mbsarquivo@yahoo.com.br \\ Universidade Federal de Santa Maria (UFSM) \\ Sônia Elisabete Constante \\ soniaeliad@gmail.com \\ Universidade Federal de Santa Maria (UFSM)
}

Resumo: $O$ presente artigo tem por finalidade relatar a existência de estratégias de preservação da informação digital nos Setores de Arquivo das Instituições Federais de Ensino Superior da Região Sul do Brasil. Com a premissa de que essas instituições desenvolvem estratégias de preservação digital em seus acervos (migração, emulação, encapsulamento, adoção de padrões, entre outras), busca-se retratar este cenário através de quatro objetivos: análise da integração dos documentos digitais nos programas de gestão de documentos das Instituições; levantamento das estratégias de preservação digital desenvolvidas nos Setores de Arquivo; identificação das unidades, além dos Setores de Arquivo, responsáveis pela aplicação de estratégias de preservação digital; e análise dos fatores que comprometem a efetivação das estratégias de preservação. Desse modo, as conclusões do estudo demonstram que há um cenário pouco efetivo na preservação da informação arquivística digital nas Instituições Federais de Ensino Superior da Região Sul do Brasil.

Palavras-chave: arquivologia; preservação digital; informação arquivística.

Abstract: This article aims to report the existence of strategies for the preservation of digital information in archives Federal Institutions of Higher Education in the South of Brazil. With the assumption that these institutions develop digital preservation strategies (migration, emulation, encapsulation, adoption of standards, among others) for their collections, seeking to portray this scenario through four objectives: analysis of the integration of digital documents in the programs document management; survey of digital preservation strategies developed in archives; identification of units in addition to the archives responsible for the implementation of strategies for digital preservation, and analysis of factors that undermine the effectiveness of conservation strategies. Thus, the findings demonstrate that there is a scenario less effective in preserving the digital archival information in Federal Institutions of Higher Education in the South of Brazil.

Keywords: archives; digital preservation; archival information.

\section{INTRODUÇÃO}

A criação de documentos e informações em formato digital suscita sua inserção em programas de gestão de documentos, para que sirvam no desempenho das tarefas administrativas e, posteriormente, se considerados de valor permanente, estejam à disposição dos mais diversos pesquisadores. 
Neste contexto, em que a informação arquivística digital se torna cada vez mais presente, este estudo tem por objetivo geral analisar a existência de estratégias de preservação da informação digital nos Setores de Arquivo das Instituições Federais de Ensino Superior (IFES) na Região Sul do Brasil. Os objetivos específicos constituem-se em analisar a integração dos documentos digitais aos programas de gestão de documentos das Instituições, levantar as estratégias de preservação digital desenvolvidas nos Setores de Arquivo, identificar as unidades - além dos Setores de Arquivo - responsáveis pela aplicação de estratégias de preservação digital, e analisar os fatores que comprometem a efetivação das estratégias de preservação. Com a premissa de que algumas IFES desenvolvem estratégias de preservação digital em seus acervos, busca-se, portanto, identificá-las, avaliando sua capacidade de garantir a preservação digital de longo prazo, levantando os fatores que influenciam sua aplicação e desenvolvimento.

A escolha das IFES da Região Sul do Brasil como universo da pesquisa, se justifica pelo período de tempo disponível para a execução do estudo (configurando-se em um período de aproximadamente dois semestres, tempo escasso para se abranger as demais regiões do Brasil), além do interesse dos autores da pesquisa, que atuam profissionalmente em estados na Região Sul do Brasil, em contribuir com tais instituições na busca de conhecimento sobre o tema preservação de documentos arquivísticos digitais.

Dessa forma, torna-se fundamental que arquivistas, acadêmicos, pesquisadores e demais profissionais envolvidos conheçam a realidade brasileira sobre gestão e preservação da informação arquivística digital. Soma-se a isso a inserção cada vez mais frequente da tecnologia voltada aos contextos informacionais, requerendo dos arquivistas novas alternativas para efetivar a gestão de seus acervos documentais em meio digital. Para que este cenário seja efetivado, parte-se do desenvolvimento, aplicação e, posteriormente, divulgação dos resultados obtidos em estudos e pesquisas.

\section{PROCEDIMENTOS METODOLÓGICOS}

A pesquisa constitui-se de um meio de busca de respostas para os problemas e indagações que se apresentam para a sociedade. Gil (2002, p. 17) define a pesquisa como "procedimento racional e sistemático que tem como objetivo proporcionar respostas aos problemas que são propostos".

Considerando que sua aplicação se desenvolve no âmbito das IFES da Região Sul do Brasil, adotaram-se critérios para delimitar as unidades institucionais a serem analisadas frente ao tema. O primeiro critério se referiu à diferenciação entre as instituições que são caracterizadas como IFES: as universidades federais e os institutos federais. $O$ foco do estudo 
delimitou-se nas universidades federais, pois são organizações que apresentam, predominantemente, setores responsáveis pela gestão de documentos arquivísticos. 0 segundo critério adotado se voltou para a existência de arquivistas (graduados em Arquivologia) no quadro permanente de servidores das universidades, uma vez que o estudo aborda preceitos arquivísticos. O terceiro critério utilizado desconsiderou da pesquisa as universidades que foram criadas recentemente, o que poderia representar políticas incipientes voltadas à gestão de documentos arquivísticos, denotando dados pouco consistentes sobre o tema pesquisado. Dessa forma, a pesquisa restringiu-se a cinco universidades, sendo que todos os estados da Região Sul (Rio Grande do Sul, Santa Catarina e Paraná) foram representados com pelo menos uma instituição.

Para a coleta dos dados, utilizou-se um questionário constituído de perguntas abertas e fechadas. Este instrumento foi enviado aos Setores de Arquivo, unidades responsáveis pela gestão de documentos arquivísticos das instituições (tais setores recebem denominações de acordo com sua estrutura organizacional, mas predominantemente conhecidos como "Arquivo Central" e "Arquivo Geral"). Gil (2002, p.115) destaca que "o questionário constitui o meio mais rápido e barato de obtenção de informações, além de não exigir treinamento de pessoal e garantir o anonimato".

Durante o período de janeiro a março de 2012 (configurando um período de três meses), os questionários permaneceram nos Setores de Arquivo, período em que os arquivistas puderam relatar as atividades que desenvolvem frente à gestão de documentos arquivísticos convencionais e digitais. Após o respectivo período, todos os Setores de Arquivo incluídos na pesquisa devolveram os questionários devidamente preenchidos, representando um índice de participação correspondente a $100 \%$ da população pesquisada, contribuindo para que os três estados da Região Sul do Brasil fossem contemplados no estudo. Na apresentação dos dados, foram atribuídas letras, de forma aleatória, representando cada instituição ( $A, B, C$, D e E), permitindo identificar fatores específicos de cada contexto, sem comprometer o caráter de anonimato.

Para facilitar a compreensão e a inter-relação que se estabelece entre os fatores pesquisados, sua apresentação é construída com base em cinco tópicos: inserção dos documentos arquivísticos digitais na gestão de documentos; políticas de preservação digital; estratégias de preservação digital desenvolvidas nos Setores de Arquivos e a perspectiva de preservação de longo prazo; estratégias de preservação em outros setores; e fatores que comprometem a efetivação das estratégias de preservação digital. Para auxiliar na argumentação das ideias expressas na pesquisa, utilizou-se um referencial teórico baseado em 
bibliografias e, principalmente, artigos científicos. Silva e Menezes (2005) destacam que a análise da literatura e de publicações permite a construção de um quadro teórico responsável pela sustentação do desenvolvimento da pesquisa.

A conclusão resultante da pesquisa representa a produção de conhecimento de interesse para a comunidade acadêmica, profissionais de diversas áreas, além do público interessado pela temática. Isso possibilita o cumprimento da função de desenvolvimento profissional e social a que se propõe a pesquisa científica.

\section{A PRESERVAÇÃO DA INFORMAÇÃO DIGITAL NOS ARQUIVOS DAS IFES DA REGIÃO SUL DO BRASIL}

Nos tópicos a seguir, apresentam-se os dados coletados nas IFES da Região Sul do Brasil frente à preservação da informação digital e sua respectiva análise de acordo com o referencial teórico da área.

\subsection{Inserção dos documentos arquivísticos digitais na gestão de documentos}

Para identificar a integração dos documentos arquivísticos digitais na gestão de documentos das IFES, aplicaram-se perguntas que abrangem o desenvolvimento da gestão documental, o apoio recebido pela administração gestora e a qualidade arquivística resultante da aplicação da gestão documental.

A gestão de documentos cumpre uma função preponderante na organização racional das informações arquivísticas, possibilitando sua recuperação ágil e facilitada, servindo de subsidio à tomada de decisão dos gestores de unidades administrativas. Segundo Bernardes (1998), a gestão de documentos reflete na racionalização, na eficiência administrativa, bem como na preservação do patrimônio documental de interesse histórico-cultural. Acrescenta-se a opinião de Carvalho e Longo (2002) esclarecendo que as organizações encontrarão na informação, no conhecimento e no planejamento os elementos que irão direcionar sua tomada de decisão, necessitando que um maior número de informações sejam processadas como apoio de suas tarefas. Neste estudo, conforme levantamento dos dados, constatou-se que a Instituição C (20\%) não desenvolve a gestão de documentos (em suporte físico), enquanto que as Instituições A, B, D e E (80\%) desenvolvem a gestão documental de modo parcial.

A Instituição A justificou que os fatores responsáveis pelo desenvolvimento parcial da gestão de documentos são: desinteresse da administração superior à qual o Setor de Arquivo está subordinado; descompasso nos procedimentos adotados no Setor de Protocolo (arquivo 
corrente) e no Setor de Arquivo (documentos predominantemente intermediários); preocupação não homogênea entre os dirigentes da instituição para com a documentação arquivística; e número de arquivistas insuficientes considerando o volume de produção e acumulação de documentos ao longo dos anos. A Instituição B relatou que o desenvolvimento parcial da gestão de documentos, se deve ao fato do sistema de arquivos ainda estar em fase de implantação. Para a Instituição D, a situação é semelhante, ao afirmar que os procedimentos de gestão documental estão sendo desenvolvidos gradativamente. Enquanto isso, a Instituição E justificou o apoio parcial, por não haver controle da produção e classificação dos arquivos correntes.

Quanto ao apoio da administração gestora para o desenvolvimento da gestão de documentos, demonstra-se um cenário em que as Instituições B, C e D (60\%) responderam que há apoio da administração, enquanto a Instituição A e E (40\%) responderam receber apoio parcial.

A Instituição C justificou que, embora o apoio recebido resulte em avanços nas atividades desenvolvidas para a gestão documental, ainda não se apresenta em um nível desejado. Isso significa que com um apoio mais efetivo da administração gestora, projetos e ações de maior amplitude poderiam ser empreendidos para se alcançar o objetivo de promoção da gestão documental.

A Instituição E relatou que existe morosidade na aprovação de projetos voltados à gestão de documentos propostos pelo Setor de Arquivo. Carvalho e Longo (2002) explicam que um sistema de arquivo é a solução encontrada pelas instituições para administrar a produção documental desde a geração ou recebimento, até alcançar a destinação final, considerando a preservação, compartilhamento e disseminação das informações geradas pelas relações internas e externas da instituição.

Destaca-se que em nenhuma das Instituições pesquisadas se considerou uma total inexistência de apoio da administração gestora. Frente a isso, propicia-se a perspectiva de continuidade dos projetos (ou proposição de novas iniciativas) visando à gestão das informações arquivísticas. O resultado das ações voltadas à gestão documental reflete na salvaguarda das informações das Instituições, além de cumprir a sua função de propiciar o seu acesso à sociedade. Sobre este último argumento, observam-se as palavras de Sousa (2006, p. 3) ao indagar "como o cidadão brasileiro poderá conhecer as informações existentes sobre ele? Isso, também, será uma ficção enquanto não Ihe for assegurado o acesso à informação, mas é necessário que ela esteja organizada, acessível e protegida." 
Com o advento das tecnologias da informação e seu uso intensificado nas últimas décadas, as instituições deparam-se com uma crescente quantidade de documentos criados e acessados por meio de equipamentos eletrônicos. Silva (2007) confirma esta questão ao explicar que a produção intensiva de informação registrada e transmitida em formato digital é o resultado da evolução social e da revolução tecnológica dos últimos 20 anos.

Avançando para a temática dos documentos digitais, averiguou-se que as Instituições A, B e D (60\%) não incluem as informações arquivísticas digitais junto a seus programas de gestão, em contraposição às Instituições C e E (40\%) que incluem apenas alguns documentos. Constata-se, portanto, que em nenhuma das Instituições há a inclusão de todos os documentos arquivísticos digitais produzidos e/ou recebidos, junto a seus programas de gestão documental.

As razões que propiciam a intensificação do uso da informação digital são muitas, mas, resumidamente, Lima (2007) explica que dentre as vantagens que a tecnologia propicia estão à agilidade e facilidade para acesso aos documentos, além da produção, transmissão e armazenamento a baixos custos, com ganho no processo de criação e troca de informação arquivística. Além disso, os recursos natos digitais não conhecem limites no que se refere à sua difusão. Rocha, Silva e Didati (2005) apresentam opinião semelhante, ao mencionarem as qualidades dos documentos digitais como economia de espaço físico, ganho de produtividade, otimização dos fluxos de trabalho, facilidade de geração e distribuição de dados e informações.

O cenário identificado nesta pesquisa remete para o desafio com o qual as instituições e arquivistas se deparam: como garantir a gestão da informação arquivística em meio digital garantindo sua autenticidade e integridade ao longo do tempo. Para se compreender as implicações que a informação digital representa, observa-se a citação de Rocha, Silva e Didati (2005) descrevendo que o documento digital trouxe para o cenário arquivístico uma saudável discussão conceitual e teórica sobre os princípios e métodos da arquivística. Esta discussão fortalece a análise das características do documento de arquivo frente à autenticidade, acessibilidade e integridade que o habilitam a ser o melhor testemunho e fonte de prova das políticas, atividades e decisões das instituições, uma vez que os documentos processados por um computador podem ser manipulados sem deixar qualquer vestígio, sendo instáveis e extremamente vulneráveis à intervenção humana.

Neste sentido, questionou-se às IFES sobre a qualidade arquivística (autenticidade, acessibilidade, confiabilidade, organicidade e unicidade) denotada às informações digitais graças ao desenvolvimento da gestão documental. As respostas correspondem às Instituições C e E (40\%) que informaram que garantem a qualidade arquivística aos documentos digitais. 
Enquanto isso, as Instituições A, B e D (60\%) não responderam, uma vez que, como verificado em questionamento anterior, não incluem as informações arquivísticas digitais no seu programa de gestão documental.

A qualidade arquivística dos documentos são fundamentais para que estes se constituam em fonte de informação autêntica, garantia de direitos e elemento de prova no contexto em que foram criados e utilizados ao longo do tempo. Rocha, Silva e Didati (2005) argumentam que os cidadãos, a sociedade e os governos dependem cada vez mais da informação digital para o exercício dos seus direitos e cumprimento das exigências de prestação de contas ao público de suas ações e decisões. Mas isto só se torna possível com documentos (convencionais e/ou digitais) investidos de qualidade arquivística.

\subsection{Políticas de preservação digital}

Na sequência, a pesquisa voltou-se às possíveis políticas de preservação da informação arquivística digital existentes nas IFES da Região Sul do Brasil, abordando aspectos como: a preocupação com a preservação digital e o conhecimento por parte dos arquivistas das diretrizes na área de preservação digital publicadas por órgãos como o Arquivo Nacional e o Conselho Nacional de Arquivos (CONARQ), bem como o atendimento do que consta nestas publicações; e o estabelecimento de diretrizes e/ou orientações referentes à preservação de documentos digitais produzidos no âmbito das próprias IFES.

Nas Instituições A, B, C e E (80\%), conforme questionários aplicados, os arquivistas demonstram preocupação com a preservação digital, embora, como ilustra a Instituição A, muitas vezes os arquivistas não participem das políticas de preservação, pois esta é de domínio da Unidade de Processamento de Dados e Tecnologia da Informação (nomenclatura adotada nesta pesquisa para denominar os "Centros de Processamento de Dados" e "Unidades de Tecnologia da Informação" das IFES). A Instituição B relatou um contexto similar, uma vez que a Unidade de Processamento de Dados e Tecnologia da Informação tem a responsabilidade de firmar ações voltadas para a preservação da informação digital. Enquanto isso, a Instituição C justificou que nas reuniões com a administração superior e servidores das unidades é possível perceber que há uma preocupação com a informação digital, fato comentado também pela Instituição $E$, destacando que há um acompanhamento constante, por parte do Setor de Arquivo, para as tecnologias e ações empreendidas aos documentos digitais que fazem parte da gestão documental ou que são gerenciados pelas tecnologias de Gestão Eletrônica de Documentos (GED).

Por outro lado, na Instituição D (20\%) não existe tal preocupação. Justificou-se, no entanto, que um plano diretor está em desenvolvimento, tendo por objetivo atender às 
necessidades tecnológicas e de informação na Instituição, contando com a participação do Setor de Arquivo para integrar os objetivos e as metas referentes à gestão e preservação de documentos arquivísticos digitais.

Pelo cenário apresentando, toma-se por referência Silva (2002), ao argumentar que a preservação de dados digitais já é um fato, sendo fundamental a construção de uma estratégia eficiente em termos de permanência por longo prazo. É necessário um engajamento mútuo e cooperativo aos que já venham desenvolvendo os mais variados trabalhos com conteúdos digitais, de forma a encontrar, nos diferentes contextos, soluções para as proposições e objetivos estipulados. Neste sentido, as IFES são unidades semelhantes em suas atribuições e objetivos de promover o ensino, a pesquisa e a extensão, e o mesmo deve avançar para outras áreas, como, por exemplo, a gestão e a preservação da informação arquivística digital, amparada por equipes multidisciplinares (arquivistas, profissionais de tecnologia da informação, bibliotecários, entre outros) capazes de desenvolver projetos consistentes e de longo prazo.

A atenção investida para a preservação digital deve iniciar na fase de produção dos documentos, como sugerem Barbedo, Corujo e Sant'Ana (2010): para possibilitar a preservação dos objetos digitais a longo prazo, devem ser aplicadas medidas de preservação logo que possível, ou seja, preferencialmente enquanto os objetos digitais são/estão ainda acessíveis e ainda em fase de produção. Evidencia-se, portanto, a importância do desenvolvimento efetivo da gestão documental nas IFES, não apenas parcial, mas que contemple toda a estrutura organizacional responsável pela produção e uso da informação digital.

No questionamento seguinte, indagou-se sobre o conhecimento - por parte dos arquivistas das diretrizes e orientações produzidas pelo Arquivo Nacional e pelo CONARQ, frente à preservação de documentos arquivísticos digitais. Os arquivistas das Instituições $A, B$, C, D e E (100\%) informaram que têm conhecimento sobre as diretrizes e orientações produzidas pelos órgãos normatizadores das políticas arquivísticas nacionais.

O índice de $100 \%$ denota um acompanhamento constante dos arquivistas para com as iniciativas voltadas à preservação digital. Este fator pode exercer influência na realização de projetos que garantam o acesso de longo prazo aos documentos arquivísticos produzidos pelas IFES. Corrêa (2010) defende que é importante conhecer detalhadamente a prática das instituições nacionais, acadêmicas e de outros segmentos, com a finalidade de traçar um panorama nacional e, então, respeitando as diferenças que provavelmente serão encontradas, 
criar frentes de atuação coordenadas para avançar no processo de preservação do patrimônio digital.

A pesquisa abordou se as orientações (que são de conhecimento dos arquivistas) são aplicadas pelos Setores de Arquivo. Da população pesquisada, as Instituições A, C e D (60\%) afirmaram que não seguem as orientações publicadas pelos órgãos normatizadores, enquanto que as Instituições B e E (40\%) responderam seguir parcialmente, considerando que apenas determinadas publicações e/ou itens são possíveis de serem atendidos. Constatou-se que, embora os arquivistas tenham conhecimento das publicações, não conseguem efetivar, ou conseguem apenas parcialmente, as diretrizes e/ou recomendações relacionadas à preservação digital. Há, portanto, o conhecimento teórico, mas sem sua eficaz aplicação que possibilitaria a efetiva preservação dos documentos arquivísticos digitais.

Por isso, ao realizar uma análise das questões anteriores sobre o desenvolvimento da gestão de documentos nas IFES, foi identificado um histórico de dificuldades na aplicação de ações para os documentos físicos, consequentemente refletindo para os documentos digitais. Para Corrêa (2010), é necessário sair do campo teórico e formalizar e começar a implantar algumas estratégias baseadas no trabalho cooperativo e na troca de experiências, mesmo que a realidade de cada instituição seja diferente. Silva (2007) complementa que a preservação digital só poderá ser realmente desenvolvida por entidades com algum poder econômico, de modo que somente com a cooperação mundial é que a preservação digital poderá se tornar uma realidade mais concreta.

Embora a pesquisa se limite ao espaço geográfico da Região Sul do Brasil, os desafios impostos à preservação digital avançam para todo o contexto nacional. Rocha, Silva e Didati (2005) destacam que, no cenário nacional, a adoção de políticas e ações que visam à preservação do patrimônio digital tem sido ainda incipiente. Para o Arquivo Nacional, em seu papel de entidade central na gestão de documentos públicos da administração pública federal, considera-se inadiável proposições e implementação de infraestrutura tecnológica apropriada para receber, organizar, preservar e dar acesso aos documentos digitais sob sua guarda.

Após verificar a aplicação das publicações oficiais, o estudo voltou-se para a identificação de diretrizes e/ou orientações referentes à preservação de documentos arquivísticos digitais produzidos pelo Setor de Arquivo. Diferente das demais, a Instituição E (20\%) confirmou a existência de tais diretrizes/orientações, relatando que as mesmas estão descritas em documentos oficiais do Setor de Arquivo, configurando-se como instrumentos que tratam sobre a preservação digital. 
As Instituições A, B, C e D (80\%) responderam não existir diretrizes/orientação do Setor de Arquivo referentes à preservação digital. A Instituição $A$ justificou que os documentos digitais não são de responsabilidade do Setor de Arquivo e, consequentemente, não se produziram instrumentos normativos para este tema. A Instituição $B$ afirmou que as normas $e$ orientações produzidas pelo CONARQ foram repassadas à "Unidade de Processamento de Dados e Tecnologia da Informação". Já a Instituição C relatou que no momento atual suas ações estão voltadas para a conscientização dos gestores da Instituição, e que os documentos digitais produzidos diariamente se acumulam, não recebendo tratamento adequado. $\mathrm{Na}$ justificativa da Instituição $D$ o respondente afirmou que ainda não foi constituído um grupo de trabalho voltado para a gestão e preservação de documentos arquivísticos digitais e, portanto, as orientações do Arquivo Nacional e do CONARQ não foram aplicadas. Entretanto, nesta Instituição já foi elaborada a minuta da resolução sobre a normalização, organização e funcionamento do sistema de arquivos da instituição, incluindo-se a gestão dos documentos digitais.

O panorama identificado remete à insuficiência de orientações produzidas especificamente pelos Setores de Arquivo, detentores de conhecimentos específicos sobre a gestão arquivística dos documentos e informações. Barbedo, Corujo e Sant'Ana (2010) comentam que quanto mais depressa a instituição integrar a preservação digital no seu plano de ação, maior será a probabilidade de sucesso na preservação dos documentos digitais.

É necessário que a instituição possua um documento estratégico que determine quais os procedimentos a serem realizados para evitar a perda das informações digitais. Rocha, Silva e Didati (2005) recomendam o desenvolvimento de uma agenda de estudos e projetos em gestão e preservação de documentos arquivísticos digitais, em parceria com instituições de pesquisa e desenvolvimento, com o propósito de obter, testar e propor metodologias, diretrizes e melhores práticas para a preservação de documentos arquivísticos.

Ao analisar os dados coletados sobre as políticas arquivísticas voltadas à preservação digital, torna-se possível identificar que esta área ainda é pouco explorada pelas IFES da Região Sul do Brasil. As razões para tal cenário, como elencados no decorrer da análise, vão desde a falta de apoio das administrações gestoras, políticas e procedimentos em fase de implantação, até ações realizadas pelas Unidades de Processamento de Dados e Tecnologia da Informação, que, em muitos casos, desconhecem os preceitos arquivísticos fundamentais para a gestão eficaz dos documentos e informações, tanto em meio convencional quanto digital. 


\subsection{Estratégias de preservação digital e a perspectiva de preservação de longo prazo}

A pesquisa seguiu com a análise de questionamentos abrangendo: a identificação das estratégias de preservação digital desenvolvidas nos Setores de Arquivo das Instituições; a frequência da adoção das estratégias; e a perspectiva de acesso de longo prazo para as informações.

Quanto às estratégias de preservação digital, a Instituição E (20\%) adota as seguintes: atualização (para suportes mais recentes) e conversão para formatos concorrentes. Dessa forma, as estratégias adotadas pela Instituição E se configuram como procedimentos de migração, que, segundo Silva (2002), é uma estratégia que visa a resolver o problema da obsolescência da tecnologia, transferindo periodicamente os dados de determinada configuração de hardware e software ou de uma geração tecnológica de computadores para outra, mantendo os conteúdos acessíveis e utilizáveis. O mesmo autor ressalta que esta estratégia necessita do levantamento prévio de requisitos como: conhecer os suportes, formatos, normas, tipos documentais, metadados, entre outros. Além disso, será necessário prover recursos para curto e longo prazo de forma a viabilizar o gerenciamento e alcançar os objetivos da preservação. Rothenberg (1999, tradução nossa) argumenta que a migração é uma estratégia que apresenta riscos, uma vez que cada ciclo de migração pode incorrer em novas perdas de informações. Além disso, dada à falta de robustez e a rápida evolução dos meios de armazenamento, os ciclos de migração poderão ser necessário com grande freqüência no espaço de tempo de poucos anos.

Enquanto isso, as Instituições A, B, C e D (80\%) afirmaram que os Setores de Arquivo não desenvolvem estratégias de preservação digital nos seus acervos. Este índice alerta para a suscetibilidade de perdas de documentos em formato digital. Isso representa, além da perda de informações de cunho administrativo, a possibilidade de descaracterização do patrimônio documental dessas Instituições. Rocha, Silva e Didati (2005) destacam que há uma grande demanda por ações de preservação digital, mas não se pode afirmar que existam certezas absolutas quanto às melhores estratégias a serem adotadas. As que têm sido adotadas até então levaram em conta fatores dos mais diversos, como aspectos legais, capacidade de investimento, foco tecnológico, sensibilização da sociedade e dos próprios governos.

Sobre a frequência da adoção das estratégias de preservação digital, a Instituição $E$ (20\%) afirmou que é realizada periodicamente, de acordo com uma política e/ou cronograma previamente estabelecido. Ao seguir um cronograma, denota-se maior possibilidade de garantir o acesso aos documentos digitais ao longo do tempo. Verificou-se que o Setor de Arquivo da respectiva instituição cumpre, portanto, a sua função primordial de garantir o 
acesso aos documentos que custodia, independentemente da forma e suporte em que se encontrem.

Quanto às demais Instituições, a Instituição A (20\%) não respondeu, uma vez que não desenvolve estratégias para preservação digital, do mesmo modo que as Instituições B, C e D $(60 \%)$ que reafirmaram não serem contempladas tais estratégias como atividades habituais. No entanto, a Instituição C (20\%) justificou que existem tentativas isoladas quanto ao desenvolvimento de estratégias de preservação, mas que inexiste uma política institucional neste sentido. Lima (2007) salienta que a tecnologia evolui de modo ágil, impelindo uma grande transitoriedade de mídias de armazenamento, formatos de arquivos, dispositivos, computadores, protocolos, sistemas, programas e suas versões e meios de difusão da informação. Ao mesmo tempo, as incertezas advindas de constantes prognósticos tecnológicos mostram a dificuldade de se definir estratégias consoantes com o futuro e alertam para a urgência de se assegurar a longevidade de uma herança cultural, histórica e científica digital. Por isso, com as incertezas envolvendo o campo da preservação digital, as instituições devem partir para suas ações de acordo com os preceitos da gestão de documentos, uma vez que este processo visa a garantir a organização, o acesso e a preservação dos documentos arquivísticos, inclusive os digitais, durante todo o seu ciclo de vida.

Quanto à capacidade das estratégias de preservação para a garantia de acessibilidade de longo prazo aos documentos digitais, os dados demonstram que as Instituições A, B e C (60\%) não responderam ao questionamento, e a Instituição D (20\%) relatou que não há estudos que definam o tempo de preservação e acessibilidade referente às estratégias adotadas e, por fim, a Instituição E (20\%) afirmou que às estratégias empregadas (atualização de suportes e conversão para formatos concorrentes) garantem a preservação de longo prazo aos documentos digitais.

Ao serem adotadas estratégias de preservação digital, viabilizam-se alternativas para que os objetos digitais permaneçam acessíveis ao longo do tempo. Portanto, a instituição $E$, ao apresentar iniciativas voltadas à migração dos seus objetos digitais, alcança até o presente momento o objetivo de manter acessível seu acervo arquivístico digital. Grácio (2011) comenta sobre a necessidade das instituições adotarem estratégias de preservação digital em suas políticas para cada tipo de objeto digital, avaliando-as periodicamente para determinar qual a melhor estratégia a ser implementada de acordo com as tecnologias existentes naquele momento. No mesmo sentido, Silva (2007) ressalta que atualmente a preservação digital é exercida através da migração de informação mediante formatos e suportes, mas, até o momento, nenhuma estratégia foi universalmente aceita. Desse modo, a escolha de uma 
estratégia depende da análise de fatores como as características do acervo, a satisfação do utilizador e os custos associados ao processo de preservação.

\subsection{Estratégias de preservação em outros setores}

Este segmento se voltou para a identificação de setores ou unidades (além do Setor de Arquivo) responsáveis por desenvolver estratégias de preservação digital nas IFES da Região Sul do Brasil. Embora no transcorrer da pesquisa algumas instituições já tenham mencionado a existência de unidades responsáveis pelo processamento de dados eletrônicos, neste tópico a questão é analisada com mais detalhes.

As Instituições A, B, C, D e E (100\%) confirmaram a existência de unidades (além do Setor de Arquivo) responsável pela efetivação de estratégias de preservação digital. Conforme justificativas, os setores que desempenham tais estratégias são as Unidades de Processamento de Dados e Tecnologia da Informação. A Instituição C relatou que outro setor a adotar estratégias de preservação digital é a unidade responsável pelos assuntos financeiros.

Em razão do índice de $100 \%$ das Instituições mantendo unidades responsáveis por desenvolver e/ou aplicar estratégias voltadas à preservação digital, levantam-se duas questões frente ao tema: por qual motivo as unidades tecnológicas predominam na área de preservação da informação digital? As ações empregadas consideram os preceitos arquivísticos da gestão arquivística de documentos?

A primeira indagação pode ser considerada de acordo com a evolução histórica do uso das tecnologias, onde as Unidades de Processamento de Dados e Tecnologia da Informação criam e desenvolvem soluções voltadas ao processamento e armazenamento de dados digitais. $\mathrm{O}$ arquivista voltou-se para as questões tecnológicas envolvidas em seu campo de trabalho há alguns anos, adentrando em um universo até então dominado por profissionais da informática, da tecnologia da informação e de áreas afins.

Com uma visão contemporânea, Grácio (2011) comenta que as instituições necessitam dispor de modelos de gestão e ferramentas tecnológicas para que as informações digitais que devem ser preservadas sejam utilizadas no futuro. Deve-se mudar o foco da estratégia tecnológica para uma visão mais ampla de gestão da informação digital, agregando cultura, serviços, políticas, tecnologias e utilizando especialistas de várias áreas.

A citação anterior aponta a resposta para o segundo questionamento: onde as Unidades de Processamento de Dados e Tecnologia da Informação raramente seguem preceitos arquivísticos de gestão da informação, pois ainda é pouco consistente a integração entre os profissionais da tecnologia com os da informação, mais ainda se considerarmos os arquivistas. Innarelli (2011) salienta que a complexidade e fragilidade dos documentos digitais 
deixam claro que a preservação digital não é resolvida pela própria tecnologia e nunca será. Esse assunto deve ser estudado de forma interdisciplinar e institucionalmente, cabendo aos profissionais da informação a garantia da preservação e manutenção do documento digital de forma íntegra e autêntica.

Grande parte das atividades desenvolvidas pelas Unidades de Processamento de Dados e Tecnologia da Informação se volta para o acesso imediato da informação, desconsiderando a preservação de longo prazo. Esse fator interfere na garantia de acesso a documentos arquivísticos digitais, que servem como fonte de prova e direitos, além de se constituírem em fonte de conhecimento e registro da trajetória institucional. Innarelli (2011) comenta que a gestão documental, ao ficar sob a responsabilidade dos profissionais da tecnologia da informação e comunicação, pode ter sido um dos maiores erros relacionados à documentação digital, pois muitos documentos podem ter sido alterados e perdidos nos diversos processos de migração de sistemas e formatos passados até hoje, além daqueles que foram perdidos em consequência da obsolescência tecnológica.

Considerando a existência de estratégias de preservação digital nas Unidades de Processamento de Dados e Tecnologia da Informação, buscou-se a identificação de quais estratégias são desenvolvidas. De acordo com a coleta de dados, demonstra-se um cenário de $20 \%$ de atualização de suportes, $20 \%$ de conversão para formatos concorrentes, $10 \%$ referente à emulação e $20 \%$ de adoção de padrões (de fato: categoria que embora não tenha sido adotada por nenhum órgão oficial de padronização é amplamente usada e reconhecida pelos usuários como tal, por exemplo, formatos PDF, TIFF, etc.; e/ou de direito: padrão utilizado por órgãos oficiais de âmbito nacional e internacionais, por exemplo, PDF/A, ODT, etc.); $10 \%$ não responderam.

As estratégias aplicadas pelas Unidades de Processamento de Dados e Tecnologia da Informação condizem com uma realidade inversamente proporcional ao constatado no âmbito dos Setores de Arquivo das IFES, uma vez que nos primeiros há uma diversidade de estratégias voltadas à preservação, enquanto que nos Setores de Arquivo as estratégias são raramente aplicadas. Além disso, a dissociação das atividades desenvolvidas pelos Setores de Arquivo e Unidades de Processamento de Dados e Tecnologia da Informação impede que soluções mútuas sejam aplicadas nas Instituições. Nesta questão, Silva (2007) reitera a necessidade de compartilhamento de conhecimento entre arquivistas e profissionais da tecnologia da informação. Deve haver uma responsabilidade partilhada, onde aos arquivistas compete a definição de normas, procedimentos e requisitos que devem informar sobre a configuração dos mecanismos de controle, garantia de autenticidade e acesso continuado aos arquivos. 
As estratégias de preservação digital desenvolvidas nas IFES (predominantemente pelas Unidades de Processamento de Dados e Tecnologia da Informação) se pautam em procedimentos de migração (atualização de suportes e conversão para formatos concorrentes), adoção de padrões e - menos frequente - a emulação. Corrêa (2010) comenta que não há um consenso sobre a melhor estratégia de preservação, apenas sugestões e relatos de instituições estrangeiras que estão experimentando propostas, analisando os resultados obtidos, as dificuldade e soluções adotadas. No Brasil, aparentemente faltam relatos deste tipo.

Complementado a questão anterior, indagou-se aos arquivistas sobre as estratégias de preservação desenvolvidas pelas Unidades de Processamento de Dados e Tecnologia da Informação que deveriam ser adotadas no Setor de Arquivo, sendo que a Instituição A não respondeu a esse questionamento. As demais responderam, como é o caso da Instituição B, que apontou a atualização de suportes, a emulação e a adoção de padrões de fato e/ou direito. A Instituição C justificou a necessidade de se observar os preceitos voltados a um Sistema Informatizado de Gestão Arquivística de Documentos (SIGAD), considerando que este inclui entre suas abordagens, preceitos para a preservação de documentos digitais. A Instituição $D$ salientou a necessidade de se aplicar todas as orientações acerca do tema emanadas do Arquivo Nacional, do CONARQ e, especialmente, da Câmara Técnica de Documentos Eletrônicos (CTDE). Enquanto isso, a Instituição E relatou a necessidade de adotar as mesmas estratégias que são desenvolvidas na respectiva Unidade de Processamento de Dados e Tecnologia da Informação.

Os relatos demonstram a expectativa dos arquivistas frente à necessidade de desenvolvimento das estratégias de preservação digital para os acervos custodiados nos Setores de Arquivo. Innarelli (2011) argumenta que a preservação digital atualmente é um dos grandes desafios da Sociedade da Informação, pois com a utilização dos recursos tecnológicos e a automação da informação, surgiu o documento digital, o qual é uma incógnita em relação à sua preservação ao longo do tempo.

Nesta pesquisa, ao se observar o reduzido número de instituições que adotam estratégias de preservação digital nos respectivos Setores de Arquivo, verifica-se a necessidade de averiguar os fatores que influenciam na constituição deste cenário. A simples constatação de que grande parte dos objetos arquivísticos digitais das IFES estão susceptíveis a perdas não contribui de forma efetiva para indispensáveis mudanças na gestão e preservação do patrimônio documental em meio digital. $\mathrm{O}$ tópico seguinte procura aprofundar esta questão. 


\subsection{Fatores que comprometem a efetivação das estratégias de preservação digital}

O levantamento e a análise dos fatores que comprometem a aplicação e o desenvolvimento de estratégias de preservação digital das IFES da Região Sul do Brasil se basearam em dois aspectos: o apoio da administração gestora e a disponibilidade de recursos financeiros, tecnológicos e humanos.

A pesquisa retrata um cenário onde as Instituições B e E (40\%) afirmaram receber apoio da administração. Com uma realidade diferente das demais, a Instituição E reiterou que os projetos do Setor de Arquivo voltados para a preservação da informação arquivística são contemplados com o apoio da administração gestora. Já a Instituição B justificou que a Unidade de Processamento de Dados e Tecnologia da Informação recebe apoio, uma vez que, como identificado anteriormente, esta é uma unidade que desenvolve ações voltadas às informações digitais.

Por outro lado, as Instituições C e D (40\%) relataram receber apoio parcial, enquanto a Instituição A (20\%) respondeu não receber apoio. Considerando que atualmente parte dos documentos arquivísticos é produzida e gerenciada em meio eletrônico e digital, os índices de ausência, ou apoio parcial, frente à preservação digital configura-se em um desafio a ser superado pelos Setores de Arquivo. A justificativa da Instituição C, recebendo apoio parcial, foi pautada no fato do processo de preservação digital estar em estágio inicial. As instituições A e D não apresentaram justificativas.

Sobre este tema, Grácio (2011) afirma que a implantação de uma política de preservação digital depende, inicialmente, da vontade da instituição, ou seja, da sua disponibilidade em investir recursos financeiros e de entender que as atividades relacionadas à preservação irão demandar tempo e uma mudança de cultural da instituição. O mesmo autor complementa que a preservação digital deve estar inserida nos objetivos da instituição.

Para os Setores de Arquivo que recebem apoio da administração gestora no desenvolvimento de estratégias de preservação digital, este fator se configura como elemento essencial para que os projetos desta área obtenham sucesso. Embora algumas das Instituições pesquisadas não apresentem políticas de gestão documental instituídas em todo o âmbito organizacional, e tampouco ações voltadas à preservação digital, o apoio recebido pela administração gestora cria condições para que projetos futuros sejam desenvolvidos e aplicados, inclusive ultrapassando os limites das atribuições do Setor de Arquivo. Mas, para Grácio (2011), além dos desafios técnicos é necessária a conscientização dos usuários e das instituições sobre a importância de se desenvolver ações de preservação digital. Criar essa cultura depende de mudanças de comportamento dos geradores da informação, das 
instituições responsáveis por preservar o que foi produzido e dos profissionais envolvidos nas atividades de preservação digital.

O segundo fator que a pesquisa identificou se refere à destinação de recursos ao Setor de Arquivo para a efetivação de procedimentos de preservação digital, onde somente a Instituição E (20\%) considera suficiente os recursos que detém. Para as Instituições A, B, C e D $(80 \%)$, os recursos são considerados insuficientes. Para que projetos de qualquer área alcancem os objetivos a que se propõe a disponibilidade de recursos é indispensável. Márdero Arellano e Andrade (2006, p. 6) argumentam que "a maioria das instituições arquivísticas possui a problemática da falta de recursos financeiros, até mesmo para as atividades básicas de sua missão."

Desse modo, o estudo levantou os fatores considerados insuficientes para a efetivação de procedimentos de preservação digital nos Setores de Arquivo. De acordo com os dados coletados, 15,79\% correspondem ao apoio da administração gestora da Instituição; $15,79 \%$ aos recursos financeiros; $21,05 \%$ aos recursos tecnológicos; $21,05 \%$ aos recursos de pessoal; $21,05 \%$ à qualificação profissional (profissionais com qualificação insuficiente na área de estratégias de preservação digital); e 5,27\% ao índice de não respondido.

Pela análise dos dados, remete-se a um cenário onde são múltiplos os fatores que interferem na inexistência de estratégias de preservação digital aplicadas aos acervos salvaguardados nos Setores de Arquivo. Inicia-se com a falta de apoio por parte da administração gestora, compreendendo desde a gestão dos documentos em suportes convencionais e, consequentemente, alcançando a preservação dos objetos digitais. Os recursos financeiros relacionam-se com os tecnológicos e, portanto, a inexistência ou insuficiência do primeiro compromete as atividades que envolvam a tecnologia aplicada à informação. Grácio (2011) explica que os investimentos nas Tecnologias da Informação e Comunicação (TICs) devem ser permanentes pela própria característica das tecnologias que se renovam continuamente. Torna-se, portanto, indispensável uma política permanente de investimento por parte da instituição, em que os custos de preservação façam parte do orçamento anual.

A orientação do autor, por mais que seja indispensável, remete para a limitação de recursos financeiros que os organismos governamentais brasileiros (incluindo as IFES) enfrentam. Esta limitação ganha proporções mais graves quando se considera que os orçamentos institucionais devem ser aplicados em diferentes áreas, sendo esta responsabilidade delegada aos gestores, os mesmos que, por vezes, não oferecem o devido apoio à gestão da informação convencional e/ou digital. Rocha, Silva e Didati $(2005$, p. 8) são 
pragmáticos ao afirmar que "outro aspecto relevante a considerar na preservação digital é a complexidade e os custos financeiros, uma vez que não existem soluções autônomas e simplificadas".

Aprofundando-se nesta questão, a escassez dos recursos de pessoal e qualificação dos profissionais contribuem para as dificuldades que as IFES enfrentam frente à preservação de seu patrimônio documental. Grácio (2011) compreende a preservação digital envolvendo várias questões: tecnológica, pois está inserida no ambiente digital, onde o objeto digital a ser preservado é descrito pelas suas características de hardware, software e suporte; profissional, pois há funcionários envolvidos nas atividades de preservação digital; processos de gestão; legal, garantindo autenticidade do objeto digital ao longo do tempo; econômica, ou seja, investimento financeiro para manter os processos de preservação que devem ser permanentes; cultural, por envolver uma mudança de atitude e de atividades das pessoas e dos grupos institucionais.

A qualificação dos arquivistas frente às estratégias de preservação digital também sobressai neste estudo. Com a mudança ágil e constante das tecnologias aplicadas à informação, há a necessidade de atualização periódica dos profissionais que atuam nesta área. Soma-se a isso o fato das estratégias estarem em constante desenvolvimento, ou seja, procedimentos até então considerados eficazes para a preservação podem ser modificados ou substituídos em detrimento de novas experiências. Andrade (2006) afirma que a evolução das tecnologias utilizadas em ambientes informacionais deve ser acompanhada e entendida pelos profissionais da informação, caso contrário não conseguirão atuar no desenvolvimento das soluções informacionais necessárias ao ambiente onde atuam. O arquivista deverá estar habilitado a exercer as diversas atividades a que se propõe, considerando as tecnologias disponíveis.

Como recomendação geral, observa-se as palavras de Grácio (2011), ao afirmar que especialmente as universidades públicas estaduais e federais passam por constantes trocas de direção, administração e recursos financeiros disponíveis, requerendo o estabelecimento de políticas permanentes para a preservação digital que sejam pouco afetadas por essas mudanças. A preservação digital deve se tornar parte integrante da política, do planejamento e dos projetos das instituições, com metas e ações definidas.

A busca por soluções visando à preservação das informações arquivísticas digitais se constitui em um processo que envolve profissionais de diversas áreas (tecnologia, informação, gestão, etc.), instituições governamentais e de pesquisa, além da própria cultura social. Para Silva (2002) a preservação dos conteúdos digitais para o futuro não é apenas um problema de 
variáveis técnicas: ao contrário, trata-se de um problema maior, relacionado com a nossa própria organização ao longo do tempo como sociedade. O esforço organizacional necessariamente envolverá fatores ainda desconhecidos ou ainda não definidos.

O desenvolvimento de estratégias voltadas à preservação da informação arquivística digital nos Setores de Arquivo das IFES da Região Sul do Brasil ainda está distante de uma situação adequada à quantidade e importância dos seus acervos documentais, representando um risco de perda do patrimônio documental.

Para representar, resumidamente, o cenário encontrado nas IFES da Região Sul do Brasil frente à preservação da informação arquivística digital, temos o Quadro 01:

\begin{tabular}{|c|c|c|c|c|c|}
\hline \multirow{2}{*}{$\begin{array}{l}\text { PRESERVAÇÃO } \\
\text { DA } \\
\text { INFORMAÇÃO } \\
\text { DIGITAL }\end{array}$} & \multicolumn{5}{|c|}{ INSTITUIÇÕES (IFES DA REGIÃO SUL DO BRASIL) } \\
\hline & A & B & C & D & E \\
\hline $\begin{array}{l}\text { Gestão de } \\
\text { documentos }\end{array}$ & $\begin{array}{l}\text { Sim, mas de modo } \\
\text { parcial. }\end{array}$ & $\begin{array}{l}\text { Sim, mas de } \\
\text { modo parcial. }\end{array}$ & Não. & $\begin{array}{l}\text { Sim, mas de modo } \\
\text { parcial. }\end{array}$ & $\begin{array}{l}\text { Sim, mas de modo } \\
\text { parcial. }\end{array}$ \\
\hline $\begin{array}{l}\text { Programas de } \\
\text { preservação digital }\end{array}$ & $\begin{array}{l}\text { Sim, de domínio } \\
\text { da Unidade de } \\
\text { Processa-mento } \\
\text { de Dados e } \\
\text { Tecnologia da } \\
\text { Informação, sem a } \\
\text { participação dos } \\
\text { arquivistas. }\end{array}$ & $\begin{array}{l}\text { Sim, de } \\
\text { responsabilidade } \\
\text { das Unidades de } \\
\text { Processa-mento } \\
\text { de Dados e } \\
\text { Tecnologia da } \\
\text { Informação. }\end{array}$ & $\begin{array}{l}\text { Não, embora } \\
\text { seja uma } \\
\text { preocupação da } \\
\text { administração } \\
\text { superior e dos } \\
\text { servidores das } \\
\text { unidades que } \\
\text { utilizam a } \\
\text { informação } \\
\text { digital. }\end{array}$ & $\begin{array}{l}\text { Não, mas um } \\
\text { plano diretor está } \\
\text { em } \\
\text { desenvolvimento, } \\
\text { contando com a } \\
\text { participação do } \\
\text { Setor de Arquivo. }\end{array}$ & $\begin{array}{l}\text { Sim, acompanhamento } \\
\text { das tecnologias e ações } \\
\text { empreendidas aos } \\
\text { documentos digitais que } \\
\text { fazem parte da gestão } \\
\text { documental ou que são } \\
\text { gerenciados pelas } \\
\text { tecnologias de GED. }\end{array}$ \\
\hline $\begin{array}{l}\text { Estratégias de } \\
\text { preservação digital } \\
\text { nos Setores de } \\
\text { Arquivos }\end{array}$ & Não desenvolve. & Não desenvolve. & $\begin{array}{l}\text { Não } \\
\text { desenvolve. }\end{array}$ & Não desenvolve. & $\begin{array}{l}\text { Desenvolve. } \\
\text { - Atualização de suportes; } \\
\text { - Conversão (formatos } \\
\text { concorrentes). }\end{array}$ \\
\hline $\begin{array}{l}\text { Estratégias de } \\
\text { preservação digital } \\
\text { em outros Setores }\end{array}$ & $\begin{array}{l}\text { Sim. } \\
\text { Unidade de } \\
\text { Processa-mento } \\
\text { de Dados e } \\
\text { Tecnologia da } \\
\text { Informação } \\
\text { - Atualização de } \\
\text { suportes. }\end{array}$ & $\begin{array}{l}\text { Sim. Unidade de } \\
\text { Processa-mento } \\
\text { de Dados e } \\
\text { Tecnologia da } \\
\text { Informação. } \\
\text { - Conversão (para } \\
\text { formatos } \\
\text { concorrentes); } \\
\text { - Adoção de } \\
\text { padrões (de fato } \\
\text { e/ou de direito). }\end{array}$ & $\begin{array}{l}\text { Sim. Unidade } \\
\text { responsável } \\
\text { pelos Assuntos } \\
\text { Financeiros. } \\
\text { - Adoção de } \\
\text { padrões (de } \\
\text { fato e/ou de } \\
\text { direito). }\end{array}$ & $\begin{array}{l}\text { Sim. } \\
\text { - (não } \\
\text { respondeu). }\end{array}$ & $\begin{array}{l}\text { Sim. Unidade de } \\
\text { Processa-mento de } \\
\text { Dados e Tecnologia da } \\
\text { Informação; } \\
\text { - Atualização de suportes; } \\
\text { - Conversão para } \\
\text { formatos concorrentes; } \\
\text { - Emulação. }\end{array}$ \\
\hline
\end{tabular}




\begin{tabular}{|c|c|c|c|c|c|}
\hline $\begin{array}{l}\text { Recursos } \\
\text { destinados ao } \\
\text { Setor de Arquivo } \\
\text { para preservação } \\
\text { digital }\end{array}$ & $\begin{array}{l}\text { Insuficientes. } \\
\text { - Apoio da } \\
\text { Administração } \\
\text { Gestora; } \\
\text { - Recursos } \\
\text { tecnológicos; } \\
\text { - Recursos } \\
\text { financeiros; } \\
\text { - Recursos de } \\
\text { pessoal; } \\
\text { - Qualificação } \\
\text { profissional na } \\
\text { área de } \\
\text { preservação } \\
\text { digital. }\end{array}$ & $\begin{array}{l}\text { Insuficientes. } \\
\text { - Recursos } \\
\text { tecnológicos; } \\
\text { - Recursos de } \\
\text { pessoal; } \\
\text { - Qualificação } \\
\text { profissional na } \\
\text { área de } \\
\text { preservação } \\
\text { digital. }\end{array}$ & $\begin{array}{l}\text { Insuficientes. } \\
\text { - Apoio da } \\
\text { Administração } \\
\text { Gestora; } \\
\text { - Recursos } \\
\text { tecnológicos; } \\
\text { - Recursos } \\
\text { financeiros; } \\
\text { - Recursos de } \\
\text { pessoal; } \\
\text { - Qualificação } \\
\text { profissional na } \\
\text { área de } \\
\text { preservação } \\
\text { digital. }\end{array}$ & $\begin{array}{l}\text { Insuficientes. } \\
\text { - Apoio da } \\
\text { Administração } \\
\text { Gestora; } \\
\text { - Recursos } \\
\text { tecnológicos; } \\
\text { - Recursos } \\
\text { financeiros; } \\
\text { - Recursos de } \\
\text { pessoal; } \\
\text { - Qualificação } \\
\text { profissional na } \\
\text { área de } \\
\text { preservação } \\
\text { digital. }\end{array}$ & Suficientes. \\
\hline
\end{tabular}

Quadro 1 - Panorama da preservação digital nos Arquivos das IFES da Região Sul do Brasil

\section{CONSIDERAÇÕES FINAIS}

A busca por soluções visando à preservação da informação arquivística digital parte de políticas que implicam o estabelecimento de ações, procedimentos e processos envolvendo os diversos profissionais (arquivistas, profissionais da $\mathrm{TI}$, gestores administrativos, etc.) que atuam com a informação, instituições governamentais e de pesquisa, além da própria cultura institucional que valorize o seu patrimônio documental. Perfaz-se, portanto, uma relação entre vários recursos que somente quando aplicados conjuntamente - e sob a égide de uma gestão consciente e eficaz - trarão resultados necessários à preservação digital.

Buscando-se conhecer a realidade atual do desenvolvimento de estratégias de preservação digital, este estudo considerou algumas das IFES da Região Sul do Brasil, a fim de examinar, identificar e avaliar a capacidade de garantir a preservação digital de longo prazo nos acervos de seus Setores de Arquivo.

Dessa forma, o estudo identificou a inexistência de políticas e programas que incluam todo o contexto documental (em meio físico) das instituições junto à gestão de documentos. Como fator determinante para a deficiência no desenvolvimento da gestão documental das IFES, foi apontada a falta de apoio da administração gestora, responsável pela tomada de decisões que influenciam nas atividades e projetos dos Setores de Arquivo. Soma-se a isto a insuficiência de arquivistas nos quadros de pessoal das IFES e a incipiente implantação de sistemas de arquivos.

Constatou-se que em grande parte das IFES há a preocupação com a preservação digital por parte dos Setores de Arquivo, mesmo que o apoio para ações neste sentido seja 
restrito, fato este observado, já que é de conhecimento dentre os arquivistas que atuam nas IFES os documentos de caráter normativo e orientador publicados por entidades como o Arquivo Nacional, o CONARQ e a CTDE, constituindo-se como passo inicial para proposições nesta área.

Quanto à aplicação de estratégias de preservação digital nas IFES foi verificada que é realizada, predominantemente, nas Unidades de Processamento de Dados e Tecnologia da Informação, onde apenas em uma das Instituições o Setor de Arquivo realiza estratégias de preservação digital (adotando a atualização de suportes e conversão para formatos concorrentes). A adoção destes procedimentos é periódica e, conforme relatou a Instituição, garante a preservação das informações por longo prazo.

Embora esta Instituição sirva como referência em ações de preservação efetivadas pelo Setor de Arquivo, o cenário geral remete para as estratégias de preservação como atribuições das Unidades de Processamento de Dados e Tecnologia da Informação. Neste sentido, constatou-se que tais unidades adotam estratégias de atualização de suportes, conversão para formatos concorrentes, emulação e adoção de padrões (de fato e/ou de direito). Isso demonstra que as ações e projetos voltados à preservação digital não são delegadas aos Setores de Arquivo nas IFES (salvo exceções), ainda que sejam estes setores os principais responsáveis pela salvaguarda do patrimônio documental.

Considerando que as Unidades de Processamento de Dados e Tecnologia da Informação são, predominantemente, responsáveis pelas estratégias de preservação digital nas IFES, recomenda-se o desenvolvimento de estudos voltados para estas unidades, com o objetivo de averiguar a consistência de suas ações voltadas à preservação digital. Mais do que aplicar estratégias de preservação, é necessário garantir que os resultados sejam efetivos na manutenção do acesso e integridade da informação arquivística ao longo do tempo, resultados estes alcançados por meio de procedimentos de gestão documental.

O desenvolvimento de estratégias de preservação pelas Unidades de Processamento de Dados e Tecnologia da Informação nas IFES remete, muitas vezes, ao não atendimento de preceitos arquivísticos, fundamentais para a adequada gestão da informação, tanto em meio convencional quanto digital. Além disso, a falta de cultura organizacional que preze pelo compartilhamento de conhecimentos e experiências entre distintas áreas (no caso da tecnologia e da gestão documental) se impõe como um obstáculo a mais na efetivação de projetos voltados à preservação da informação digital de longo prazo. Dessa forma, é necessária a integração entre os conhecimentos dos arquivistas e dos profissionais da 
tecnologia da informação, na busca de soluções que garantam efetivamente a gestão e preservação da informação.

A identificação dos fatores que comprometem a efetivação das estratégias de preservação digital é fundamental para compreender o cenário em que se encontra a preservação da informação digital das IFES da Região Sul do Brasil. Constatou-se que a maioria das Instituições considera insuficientes os recursos destinados aos Setores de Arquivo para o desenvolvimento de estratégias de preservação digital. Predomina a falta de recursos financeiros, tecnológicos, de pessoal e qualificação profissional, além da falta de apoio da administração gestora. O contexto tecnológico informacional exige investimentos constantes para atingir a finalidade de gerenciar, compartilhar e recuperar objetos digitais. Pelo que foi retratado nesta pesquisa, as IFES não estão preparadas para tal cenário.

A mudança deste contexto, em que a gestão e a preservação da informação arquivística são atividades colocadas em segundo plano nas ações das IFES, parte da sensibilização dos gestores das instituições, pois, como constatado na pesquisa, a deficiência no apoio às atividades dos Setores de Arquivos bem como a limitação de recursos comprometem iniciativas e projetos dos quais as instituições necessitam para efetivar a gestão de seus ativos informacionais.

De modo que são poucos os relatos de instituições públicas brasileiras voltados a programas de preservação digital. A atuação do Arquivo Nacional, do CONARQ e da CTDE em busca de soluções que possam ser aplicadas pelas instituições desperta para uma mudança no cenário nacional frente a este tema. Além disso, os projetos desenvolvidos internacionalmente demonstram que o contexto mundial se volta para o uso da informação digital, buscando concomitantemente soluções para sua gestão e preservação.

Conclui-se que a pesquisa retrata um panorama pouco efetivo na preservação da informação arquivística digital, mesmo que os arquivistas estejam conscientes desse desafio. As IFES da Região Sul do Brasil ainda não apresentam ações eficazes na preservação de longo prazo das informações digitais, e isso provavelmente tem origem na debilidade dos programas de gestão documental, elemento imprescindível para qualquer ação voltada à informação arquivística. 


\section{Referências}

ANDRADE, R. S. Tecnologia, memória e a formação do profissional arquivista. Arquivística.net (www.arquivistica.net), Rio de Janeiro, v.2, n.1, p.149-159, jan/jun. 2006. Disponível em: < https://desenvrepositorio.ufba.br/ri/bitstream/123456789/2366/1/AN-2006-40.pdf >. Acesso em: 12 abr. 2013.

BARBEDO, F.; CORUJO, L.; SANT'ANA, M. Recomendações para a produção de Planos de Preservação Digital. V. 2 - Direção Geral de Arquivos - DGARG, 2010. Disponível em: < http://dgarq.gov.pt/files/2008/10/PlanoPreservacaoDigital V2-02.pdf>. Acesso em: 04 mar. 2013.

BERNARDES, I. P. Como avaliar documentos de arquivo. São Paulo: Arquivo do Estado, 1998. (Projeto como fazer, 1). Disponível em: < http://www.arquivoestado.sp.gov.br/saesp/texto pdf 10 Como Avaliar Documentos de Ar quivo.pdf >. Acesso em: 22 mai. 2013.

CARVALHO, E. L.; LONGO, R. M. J. Informação orgânica: recurso estratégico para tomada de decisão pelos membros do Conselho de Administração da UEL. Informação\&Informação. Londrina, v. 7, n. 2, p. 113-133, jul./dez. 2002. Disponível em: < http://www.uel.br/revistas/uel/index.php/informacao/article/view/1703>. Acesso em: 12 de ago. 2012.

CORRÊA, A. M. G. Preservação digital: autenticidade e integridade de documentos em bibliotecas digitais de teses e dissertações. Dissertação. Escola de Comunicações e Artes Universidade de São Paulo. 2010. Disponível em: < http://www.teses.usp.br/teses/disponiveis/27/27151/tde-05112010-105831/pt-br.php>.

Acesso em: 29 jan. 2013.

GIL, A. C. Como elaborar projetos de pesquisa. 4a ed. São Paulo: Atlas, 2002.

GRÁCIO, J. C. A. Preservação digital na gestão da informação: um modelo processual para as instituições de ensino superior. Tese. Faculdade de Filosofia e Ciências - Universidade Estadual Paulista. Marília, SP, 2011. Disponível em: < http://www.marilia.unesp.br/Home/PosGraduacao/Cienciadalnformacao/Dissertacoes/gracio jca do mar.pdf $>$. Acesso em: 12 abr. 2013.

INNARELLI, H. C. Preservação digital: a influência da gestão dos documentos digitais na preservação da informação e da cultura. Revista Digital de Biblioteconomia e Ciência da Informação, Campinas, v. 8, n. 2, p. 72-87, jan./jun. 2011- ISSN: 1678-765X. 2011. Disponível em: < http://www.sbu.unicamp.br/seer/ojs/index.php/rbci/article/view/487>. Acesso em 06 abr. 2013.

LIMA, C. C. Preservação digital: experiência da Pesquisa Guinard. Dissertação (Mestrado em Artes) - Escola de Belas Artes da Universidade Federal de Minas Gerais (UFMG), Belo Horizonte, $2007 . \quad$ Disponível em:

http://www.bibliotecadigital.ufmg.br/dspace/bitstream/handle/1843/VPQZ-

76CQVW/preservacaodigitalpqg.pdf?sequence=1>. Acesso em: 24 mar. 2013. 
MÁRDERO ARELLANO, M. Á.: ANDRADE, R. S. Preservação digital e os profissionais da informação. DataGramaZero - Revista de Ciência da Informação - v.7, n.5, out/2006. Disponível em: < http://www.dgz.org.br/out06/Art 05.htm>. Acesso em: 24 fev. 2013.

ROCHA, C. L; SILVA, M.; DITADI, C. Gestão e preservação de documentos arquivísticos digitais. In: IV Congresso de Arquivologia do Mercosul (CAM). Anais. Campos do Jordão - SP, 2005.

ROTHENBERG, J. Ensuring the longevity of digital information. Feb. 1999. Disponível em: < http://www.clir.org/pubs/archives/ensuring.pdf>. Acesso em: 05 ago. 2013.

SILVA, R. R. G. Digitalização de acervos fotográficos públicos e seus reflexos institucionais e sociais: tecnologia e consciência no universo digital. 2002. Tese (Doutorado em Ciência da Informação) - Universidade Federal do Rio de Janeiro, Escola de Comunicação - UFRJ/ECO; Instituto Brasileiro de Informação em Ciência e Tecnologia - IBICT, 2002. Disponível em: <http://www.twiki.ufba.br/twiki/pub/Cridi/Publica\%E7\%F5es/rubenssilva52002.pdf>. Acesso em: 03 fev. 2013.

SILVA, C. O. P. F. A questão da preservação digital numa perspectiva orientada segundo o Open Archival Information System. Universidade de Évora. Mestrado em Arquivos, Bibliotecas e Ciência da Informação. Portugal. 2007. Disponível em: <http://coleccoesdigitais.wdfiles.com/local--files/documentos-de-apoio-preserv-digital/Tese >. Acesso em: 08 fev. 2013.

SILVA, E. L.; MENEZES, E. M. Metodologia da pesquisa e elaboração de dissertação. 4a ed. Florianópolis: Universidade Federal de Santa Catarina - UFSC. 2005.

SOUSA, R. T. B. O arquivista e as políticas públicas de arquivo. Congresso Nacional de Arquivologia - II CNA. Porto Alegre - RS. 2006. Disponível em: < http://repositorio.bce.unb.br/bitstream/10482/1026/1/EVENTO ArquivistaPoliticaPublicaArqu ivo.pdf>. Acesso em: 15 mai. 2013. 